\title{
Apply constitutional and legislative texts relating to the non- retroactivity of laws to administrative decisions
}

\author{
Torkan Ibrahim Ali \\ torkan.ali@ntu.edu.iq \\ Northern Technical University - Technical Institute, Kirkuk \\ Legal Management Technologies Department
}

\begin{abstract}
In some cases, the interest of the higher society may require legislation to apply to the past even in a situation where it is prejudicial to the interests of certain individuals. In some cases, the principle of non-retroactivity of legislation may also be lacking, as is the case in legislation that eliminates or mitigates a crime (The most appropriate low to the accused), The principle of non-retroactivity of the administrative decision is intended not to be applied to the facts and legal acts that took place before a specified time for the date of validity of the decision, and it is understood that the administrative decision can't produce its effects for the past, ie before its publication or publication. The reason for this is that the issuance of the administrative decision includes a retroactive effect that is a departure from the principle of nonretroactivity of these decisions. The principle of non-reaction is restricted to freedom of administration, and it must be codified so that the administration does not expand these decisions by reference in the administrative decision. From chaos and turmoil, by limiting the reaction in a narrow circle required by this exception, and not to expand it.
\end{abstract}

keywords: Constitutional texts, Non-retroactivity of laws, Administrative decisions

\section{Introduction:}

The basic rule of law is that it should not be valid except the date of issuance, as it does not apply to the past, but rather applies to the facts and behaviors that occur in the future while keeping their past effects intact. Accordingly, legal action, whether it is an administrative or legal decision when it is completed and issued by the competent authority to issue it, this is the beginning of its entry into a new stage called the stage of entry into validation, and this stage is the one who determines the application of the decision in terms of its temporal dimension, and in line with the legal rule that states (The branch follows the original) [1] Therefore, the administrative decision is considered a legal act that affects the existing legal centers either by amending, canceling or establishing a new legal center, so there is no harm in applying non-reactionary in the field of administrative decisions as it is applied in the field of legislation, given that each of them is legal behavior, therefore the decision The administrator is pleased A direct impact from the date of its entry into force, does not apply to what has been legal centers before [2]. The problem of the study: What is the extent of applying the constitutional and legislative texts on the non-retroactivity of administrative decisions in positive law.

The hypothesis of the study: There is a disparity in the application of constitutional and legislative texts on the non-retroactivity of administrative decisions. Importance of the study: The importance of the study lies in the principle of justice and equality and not prejudice the rights acquired by the individual against management decisions.

Aim of the study: The study aims to eliminate ambiguity in the principle of non-retroactivity in administrative decisions, and to identify the concept, justifications and basis of this principle. Study methodology: The study relies on the analytical approach to texts and decisions that included the principle of non-reactionary in administrative decisions. Structure of the study: Based on the foregoing, we will address in this study the concept of non-retroactivity in administrative decisions by explaining its principle in positive law and establishing it through two topics, as follows:

The first topic: The principle of non-retroactivity in administrative decisions in positive law.

The second topic: Establishing the principle of non-retroactivity in administrative decisions on constitutional and legislative texts in positive law.

\section{The first topic: The principle of non-retroactivity in administrative decisions in positive law Preface:}

What is meant by the principle of non-retroactivity of the administrative decision is the inadmissibility of its application to the facts and legal actions that took place before a specific time of the effective date, and it is understood from that that the administrative decision cannot produce its effects in relation to the past, that is, before publishing or announcing it. The reason for this is that the issuance of the administrative decision, 
including a retroactive effect, is a departure from the principle of non-retroactivity of these decisions, which leads to chaos, confusion and instability in legal centers, in addition to its waste of the principle of legal security, which requires a degree of stability and stability in legal relations, and whether they are These relations between individuals, or between them and the state [3].

The first requirement: the concept of non-retroactivity in the administrative decision in positive law. When referring to the opinions of French jurisprudence and the judiciary, we find that he showed the meaning of non-reaction in administrative decisions, where we cite what Professor\{ Dujuit\} said: that organizational administrative decisions are retroactive if they affect individual centers or affect previous facts [4]. While others see that the principle of non-retroactivity of the administrative decision means "the inadmissibility of the application of the administrative decision to actions and legal facts that took place before the date set for its entry into validation, but its validity is limited to what happens from the facts and works after the effective date [5]. If there is an exception to the rule Non-retroactivity in the administrative decision, as it is an exception that does not violate the wisdom and reasoning of this original. If the exception is a case if the administrative decision was issued in implementation of a law, then it is required in this case that this law has been stipulated in the retroactive effect or the administration's authorization to report retrogression, and This is what the Egyptian Supreme Administrative Court went to in a judgment issued on 4/5/2002 that: "The general rule is the enforcement of administrative decisions from the date of their issuance, Where it applies in relation to the future and does not apply retroactively to facts earlier than the date they were issued This is in respect of acquired rights or self-centered legal positions, and therefore, it is not permissible in any way to report retroactively to administrative decisions unless the law stipulates that...[6].

It is clear from above that the principle of non-retroactivity in administrative decisions means that decisions do not apply to the period prior to its enforcement, and this meaning has been confirmed by both jurisprudence and the judiciary in both France and Egypt, in order to preserve the acquired rights, and stability of Subjectivity centers.

The second requirement: the concept of reaction in administrative decisions.

The principle of non-retroactivity, although clear in its content, but its application is shrouded in some ambiguity according to the difference of opinion and the accuracy of practical assumptions in defining the meaning of reaction, and administrative jurisprudence has shown a dispute over defining a true meaning of reaction, and two opinions emerged in this field, the first takes the narrow concept, The other takes the broad concept, namely:

The first opinion: The opinion of its supporters is that reaction is an application that occurred on centers and took place during the past, and thus the decision is retroactive according to this view if its application was prior to its validity, and this is achieved in two cases: the first: is the state of application of the decision as a consequence of its taking, and the second case: that the decision is applied Subsequently to take it before its entry into validation, which is published or notified according to the decision The debate is about, or when an individual decision withdraws an advantage on a date prior to its announcement [7].

The second opinion: Which takes the broad concept and sees its supporters of reaction, which according to their understanding means the effects that an administrative decision can make in relation to the past tense, whether it is represented by events that occurred before the issuance of the decision or in the application of that decision in relation to the future to centers that arose before its issuance [8].

The reaction is dangerous according to what is agreed upon by jurisprudence and administrative judges, as it allows instability and confusion to enter the situation and previous legal actions, Nevertheless, we must know when the administrative decision came into force in terms of time and its implementation towards those who addressed it, and here there is a question that arises: Is this beginning the date of the decision, or the date of publication or announcement? And to answer it, two forms of reaction must be indicated in administrative decisions, because the reaction does not take only one form of work, but rather takes two forms as follows:

First: The retroactivity of administrative decisions with consideration to the date of signature.

There is a general rule in the validation of administrative decisions that the decision, whether organizational or individual, does not extend its effects to the date prior to the date of its signing, because the extension of these effects to this date leads to a retrogression in the decision, and this contravenes an important legal principle which is the principle of non-retroactivity of administrative decisions. As the decision stigmatizes retroactivity, whether its effects extend to one day prior to the date of signing, or these effects extend for a year prior to the date of its signature, the defect here arises and is achieved regardless of the length of the period prior to the signature or its shortening, and this defect is a defect of illegality [9]. 
The retroactivity of administrative decisions may be implicit or stable, as the decision sets a date for effective prior to its issuance, and subsequently to be published or announced, yet it appears from the content of the decision that it includes organization or amendment in the existing legal centers whose elements have been integrated before the decision is issued in effect. This is the predominant case in practice. Since it was easy to know the decision that has a retroactive effect by comparing the date of its issuance with the date of its validity, as is the case with explicit reaction, the matter differs in implicit reaction, Therefore, the administration has to resort to many means to conceal the reaction in the decisions it makes, and from these means the following:

1. The administration may make a change to the date of the decision, by submitting the date, and it included in its decision a date prior to its real date. And implement the decision from this date, and in most cases, the administration will resort to presenting the date in its decision in the event that the law stipulates its interference during a specific period, or if its interference becomes invalid, and in this case the administration will resort to providing the date to hide its interference after the deadline, and it may also resort To submit the date of the bylaw that is required before issuance of decisions to hide the illegality In this case, the administration will resort to submitting the date to hide its interference after the deadline. It may also resort to presenting the date of the regulations that are required to be issued before issuance of decisions to hide the illegality in decisions issued in implementation of these regulations before they are actually issued [10].

2. The administration also resorted to concealing the retroactivity of its decisions, as it omits to include in the decision the date of its issuance. However, this omission is not considered a defect leading to nullification of the decision, but it raises doubts in the same judge about the validity of the decision, if it is proven to him that the date of publication or announcement is prior to the effective date It has become reactionary, In any case, the effects of the decision that does not include a date or the decision with a defective date begins only from the date of its actual issuance.

3. Finally, the administration will issue a decision ordering its validity from the date of issuance or from the date of publication against the stakeholders concerned with its rulings. However, the decision includes a retroactive effect, due to his prejudice to a previous legal position that may not be prejudiced, such as the decision issued to promote an employee and after a lapse of time for its issuance, another decision is issued to amend this promotion, and in this case the previous decision is retroactive because it touched a full-fledged legal center

Second:The retroactivity of administrative decisions According to the date of publication.

On the part of French jurisprudence, the term virtual reaction to this image was coined in reaction, due to the fact that the decision specifying its effects a date later on the date of its signature or on the date of its publication manipulates the time limits, and if this manipulation is in a way less than that decision whose effects extend to a date It is totally absent in it [11].

One of the following matters agreed upon by the judiciary and confirmed by jurisprudence is that the administrative decision is complete and productive for its effects as of its issuance from the competent authority, but with regard to individuals, it can not be invoked when confronting them except after the date of their knowledge of the media such as advertising or publishing according to the conditions [12]. In spite of the above confirmation, we find a number of jurists departing from this trend, and accordingly, we will review these two trends as follows:

The first direction: which sees that the decision produces its effects from the moment it was issued, and this is what was decided by the French State Council, which believes that the administrative decision exists since its signature from its source, and that becomes binding on the administration even before its publication or notification [13].

The second direction: which the owners believe that the administrative decision is only completed by publicity, as this trend calls for the administrative decision to be completed only by issuing it from the competent authority and publicizing it and announcing it to the concerned parties. We mention here what the Greek jurist (Stasna Paulus) said that the decision remains merely a psychological incident that has no legal significance, neither for the administration nor for individuals except by its publication or announcement [14]. From the foregoing, it can be said that it is not possible to accept what was stated by the owners of the first trend to launch it, but it is necessary to observe the restriction in that and that what was stated in the second direction is closer to the right, and the summary of the above is that the decision whenever it is determined by a date prior to the knowledge of the authority implementing the decision or Previous knowledge of individuals, even if after the issuance of the decision, this is considered a departure from the principle of retroactivity (Non- retroactivity) of the administrative decision. 


\section{The second topic: Establishing the principle of non-retroactivity in administrative decisions on constitutional and legislative texts in positive law}

A part of the French jurisprudence established the principle of non-reactionary in administrative decisions based on the text of the second article of the French civil codification. As for Arab jurisprudence, some jurists see that the constitutional and legislative texts, even if they are not valid, are a basis for prohibiting all decisions, but they are suitable in some cases, such as regulations that have the force of law as well as criminal regulations [15].

While another side sees the invalidity of the constitutional and legislative texts as a legal basis for the principle of non-retroactivity of decisions even if they are at the level of legislation because they will remain in their administrative capacity, while we find that the Egyptian administrative judiciary established the principle on the constitutional texts that prohibited reaction in the laws only as an exception and not on general principles, which are considered the title of the French administrative judiciary in this field [16]. Based on the foregoing, this topic was divided into two requirements:

The first requirement: the constitutional and legislative texts related to the non-retroactivity of laws. The French constitutions affirmed, through their texts, that criminal laws do not apply to the past, to the extent that some French constitutions have generalized this principle and made it include both criminal and civil laws, on the basis that this principle is one of the guarantees of rights and freedoms and a basis of the foundations of the constitutions, This is an indication of the constitutional legislator's inclination to strictly restrict both the legislator and the judge in this principle [17].

Article (2) of the Iraqi Penal Code No. 111 of 1969 stipulates that (if one or more laws were issued after the crime was committed and before the verdict issued in it became final, the most appropriate law will be applied to the accused) [18].

However, the supreme interest of society may sometimes require that the legislation be applied to the past, even if the interests of some individuals are affected, and also wisdom may be excluded from the principle of non-retroactivity in legislation on occasion, as is the case in legislation that cancels a crime or reduces its punishment, or abrogates an unjust legal rule or decide a just rule [19].

And since the French constitutions did not include a text prohibiting reaction in non-criminal laws, the Egyptian constitutions generally included this matter in most of their constitutions, since the 1971 constitution stipulated in Article (187) that the provisions of the laws do not apply except from the date of their implementation, and that there are no implications for them In what happened before it, however, it is permissible in other than criminal articles to stipulate in the law otherwise with the approval of the majority of the members of The parliament [20], and this is stipulated by its current constitution (Constitution of 2014) in its Article (95). On a law, no punishment is imposed except by a court ruling, and there is no punishment except for actions subsequent to the effective date of the law" [21]. We discover from the foregoing that the Egyptian constitutions did not stipulate the principle of non-retroactivity in administrative decisions, but only limited to determining the principle of non-retroactivity in relation to laws in general and criminal ones in particular.

Accordingly, it can be said that the principle of non-retroactivity in administrative decisions is due to previous constitutional or legislative texts prohibiting reaction in-laws as a general rule, but it permits this reaction if stipulated in a special text, and this exception is conditional on several conditions:

1. Imposing the constitution to enable the sympathy of the law for the past to be done by a special majority, which is the approval of a majority of members of Parliament, not just a majority of those present.

2. The constitutional legislator has made the principle of non-retroactivity in criminal laws absolutely, because the stipulation of the retroactivity of criminal laws is more dangerous than a stipulation of retroactivity in ordinary laws, and therefore the principle of non-retroactivity in criminal laws is binding on both legislator and judge.

3. It is stipulated in the text on the reaction that it be explicit, as it is not permissible for the retroactive effect to be implicit, or assumed from the will of the legislator because it is an exception that the judge does not extract from his preparations for the law, nor from his own nature or from his interpretation if the will of the legislator is not explicit and not Clear in the approval of reaction, it must be said that it is not, because it is the origin.

The second requirement: applying the constitutional and legislative texts relating to the nonretroactivity of laws to decisions.

The application of constitutional and legislative texts relating to the non-retroactivity of laws over decisions is divided into two parts, the first on regulations and the second on individual administrative decisions, and will be dealt with as follows: 


\section{First: Regulations:}

The regulations include abstract general rules that are not directed at specific persons, or with a particular case in itself, they are very similar to the legislation or laws, they are issued by the executive authority, which is an authority that specializes in legislation by exception, so the Egyptian constitutional legislator did not miss this fact, as it did not decide Article (66) of the constitution states that "there is no crime and no punishment except by law." However, its decision was that "there is no crime and no punishment except based on a law." Thus it has given way to regulations as they are issued according to law [22]

With regard to the Egyptian administrative judiciary, its combined decisions have been taken to refer in the report the principle of non-retroactivity in administrative decisions to the constitutional texts that decided not to revert laws, as the Egyptian Administrative Judicial Court relied on a constitutional basis in prohibiting the retroactivity of regulations, the Supreme Administrative Court has decided in Constitutional texts are the basis for the rule of non-reactionary in administrative decisions, as it was done to describe the decision that contained a retroactive effect as unconstitutional, as it violates the constitutional rules to the duty of the administration to observe when issuing its decisions, according to the principle of legality [23].

This is that the constitution or the law gives the executive authority specific legislative powers, and the texts issued by it are considered legislation, and accordingly, these texts issued by them are valid to be a source of legislation and punishment, and this is confirmed by what was stated by a part of the jurisprudence in defining the regulations as sub-legislation that the executive authority is concerned with its status According to the constitutional provisions in the country [24]. Therefore, we can say that the legislature is not only required by the legislature, but rather it is issued by an authority that is competent for legislation.

\section{Second: individual administrative decisions}

Since the laws are abstract general rules that apply to an unspecified number, in particular, the individual administrative decisions that face individual cases are not laws, and therefore the term laws mentioned in the constitutional texts or in various legislations do not deviate to individual administrative decisions, and the constitutional prohibition of non-retroactivity Legislation, except by an explicit text, prohibits the legislative texts from being interpreted with a retroactive effect, in addition to these legislative texts that do not allow the administration to apply the legislation or implement it with a retroactive effect unless the legislator wants to do so [25].

And that the individual administrative decisions issued in implementation of a general organizational rule do not include a retroactive effect unless the general organizational rules are permitted to do so, and therefore the basis for the prohibition of reaction in individual decisions is the same as the basis for the prohibition in Legislation as well as in the ritual decisions, but if the issuance of individual decisions is independent without It is an application of a general organizational rule, in this case, it cannot be said as a general rule that the legal basis for prohibiting its legitimacy is the legislative or constitutional texts that prohibit the retroactivity of laws [26], but its basis appears in the general principles of the law.

\section{Conclusion}

As we have finished our research on the principle of non-reactionary in administrative decisions, a set of results has been reached regarding the subject of this research and some recommendations that the researcher considers and we can summarize as follows:

First: Search results:

- The correct basis for the principle of non-retroactivity in administrative decisions lies in the constitutional texts that do not allow reaction in-laws except as an exception.

- If the legislator can provide for retrogression as the principle of non-retroactivity has a legislative value, with the exception of criminal matters, it is of constitutional value, he may authorize the administration to issue executive decisions for this reactionary legislation either explicitly or implicitly.

- The research found that jurisprudence and justice, whether in France or Egypt, permitted the issuance of reactionary decisions in violation of the general principle, when that was in the public interest, as in the case of decisions that include a specific group of people and during a specific period.

Second: Recommendations:

- The researcher recommends reducing the rigor of the non-reactionary rule in administrative decisions whenever it is in the interest of the individuals addressed to the provisions of the decision. Because this aim of justice from the non-reactionary rule report is towards the benefit of individuals, since achieving retrogression does not harm others.

- The principle of non-reactionary is a restriction on the freedom of administration, and it must be codified so that the administration does not expand to change those decisions by referring to the administrative 
decision, which would protect legal relations from chaos and turmoil, by restricting reaction in a narrow circle required by this exception, and not expanding it.

\section{References}

[1] Mohamed Fouad Abdel Baset, Administrative Decision, Dar Alfikr Alarabi, Alexandria, Egypt, 2000, p. 400.

[2] Suleiman Al-Tamawi, General Theory of Administrative Decisions, 1 st edition, 1991, p. 548.

[3]Yusri Al-Assar, Constitutional Protection of Legal Security in the Judiciary of the Constitutional Court, article in the Constitutional Magazine, first year, 2003, No. 3, p. 51.

[4] Nasser Abdel Halim Al-Salamat, Implementation of the Administrative Decision in the Jordanian Administrative Law, PhD Thesis, Faculty of Law, Ain Shams University, 2009, p. 174.

[5] Aad Hammoud, The Brief in Administrative Law, Dubai Police Academy, 2004, p. 353.

[6] Judgment of the Egyptian Supreme Administrative Court in Appeal No. 6313 of 45 session 4/5/2002, Encyclopedia of the rulings of the Supreme Administrative Court.

[7] Nasser Abd Al-Halim Al-Salamat, Implementing the Administrative Decision in the Jordanian Administrative Law, previous source, p. 174.

[8] Ahmed Abdel-Haseeb Abdel-Fattah, the retroactive effect of the administrative and constitutional judgments, a comparative study between law and Sharia, Arab Renaissance House, Cairo, Egypt, 2011, p. 234.

[9] Abdel-Aziz Al-Gohary, Law and Decision between the Issue and the Publicity, PhD Thesis, Cairo University, Faculty of Law, 1975, p. 73.

[10] Mahmoud Helmy, The Effectiveness of Administrative Decision in Time, PhD Thesis, Faculty of Law, Cairo University, 1972, p. 74.

[11] Mahmoud Helmy, ibid., P. 70.

[12] Abdul-Aziz Al-Jawhar, Law and Decision in the Period between Issue and Publicity, previous source, p. 75.

[13] Hamdi Abu Al-Nour Al-Sayed, Amal Lotfi Hassan, The brief in Administrative Law, Arab Renaissance House, 2006, p. 336.

[14] Muhammad Youssef Al-Hussein, Muhannad Noah, Administrative Law, Damascus University, Syria, 2011, p. 193. [15]Muhammad Ahmad Ibrahim Al-Musallmani, The Execution of Administrative Decisions with Retroactive Effect, New University House, Alexandria, 2014, p. 199.

[16]Sami Jamal Al-Din, Fundamentals of Administrative Law, Al-Maarif Institution, Alexandria, 1998, p. 26.

[17]Raheem Al-Kubaisi, Freedom of Administration to Withdraw its Decisions, PhD Thesis, Cairo University, 1986, p. 70 .

[18]Article (2) of the Iraqi Penal Code No. 111 of 1969.

[19]Ahmed Abdel-Haseeb Abdel-Fattah, the retroactive effect of the administrative and constitutional judgments, a comparative study between law and Sharia, Arab Renaissance House, Cairo, 2011, p. 271.

[20]Article 187, the Egyptian constitution, 1971.

[21]Article 95, Egyptian Constitution, 2014.

[22]Article (66), Egyptian Constitution, 2006.

[23]Muhammad Ahmad Ibrahim al-Muslamani, The Execution of Administrative Decisions with a Retroactive Effect, Previous Source, p. 212.

[24]Mohsen Khalil, Lebanese Political and Constitutional Systems, Arab Renaissance House, 1985, p. 330.

[25]Muhammad Ahmad Ibrahim, Ibid, p. 213.

[26]Mahmoud Helmy, The Islamic Regime in Comparison with Man-made Systems, 4th Edition, Dar Al-Huda, 1980, p. 250. 